\title{
Occupational Exposure to Solar UV Radiation in a Group of Dock-workers in North-East Italy
}

\author{
Alberto Modenese \\ Dept. of Biomedical, Metabolic and \\ Neural Sciences \\ University of Modena \& Reggio Emilia \\ Modena, Italy \\ alberto.modenese@unimore.it
}

\author{
Chiara Burattini \\ Dept. of Astronautical, Electrical and \\ Energy Engineering, \\ University of Rome "Sapienza", \\ Rome, Italy \\ chiara.burattini@uniroma1.it
}

Andrea Militello

Dept. of Occupational and Environmental

Medicine, Epidemiology and Hygiene,

Italian Workers' Compensation Authority (INAIL-DiMEILA)

Monte Porzio Catone (Rome), Italy a.militello@inail.it

\author{
Fabio Bisegna \\ Dept. of Astronautical, Electrical and \\ Energy Engineering, \\ University of Rome "Sapienza", \\ Rome, Italy \\ fabio.bisegna@uniroma1.it
}

\author{
Luca Gugliermetti \\ Dept. of Astronautical, Electrical and \\ Energy Engineering, \\ University of Rome "Sapienza", \\ Rome, Italy \\ luca.gugliermetti@uniroma1.it \\ Paolo Toffanin \\ Unit of Prevention and Safety in \\ Workplaces, \\ Dept. of Prevention - A.S.U.I.T.S \\ Trieste, Italy \\ paolo.toffanin@asuits.sanita.fvg.it
}

\author{
Massimo Borra \\ Dept. of Occupational and Environmental \\ Medicine, Epidemiology and Hygiene, \\ Italian Workers' Compensation Authority \\ (INAIL-DiMEILA) \\ Monte Porzio Catone (Rome), Italy \\ m.borra@inail.it
}

Francesca Larese Filon

Unit of Occupational Medicine,

University of Trieste,

Trieste, Italy

larese@units.it

Fabriziomaria Gobba

Dept. of Biomedical, Metabolic and Neural Sciences

University of Modena \& Reggio Emilia

Modena, Italy

fabriziomaria.gobba@unimore.it

\begin{abstract}
Occupational solar ultraviolet radiation (UVR) exposure is a relevant heath risk in dock workers, potentially exposed to both direct and reflected radiation, but apparently was scantly studied up now and few studies on measurements of solar UVR levels are currently available for these workers. Our aim was to provide an evaluation of UVR exposure in $\mathbf{1 0}$ longshoremen and 4 port traffic coordinators/goods acceptors of a dock in North-East Italy. During a Summer day, workers' exposure was measured with personal UV dosimeters, and the environmental UV effective radiant exposure with a spectroradiometer. Personal solar UV dose ranged between $257-1975 \mathrm{~J} / \mathrm{m} 2$ in longshoremen, and between $44-139 \mathrm{~J} / \mathrm{m} 2$ for port traffic coordinators/goods acceptors. The percentage of personal compared to ambient exposure resulted between 16 and $59 \%$ for longshoremen, while were much lower, between 2 and $7 \%$, in port traffic coordinators/goods acceptors. Eye exposure was also estimated using an ocular UV dosimeter placed on a stem of the sunglasses in a subject spending the day close to the longshoremen, resulting in a non-weighted solar UV-A ocular dose between 133.9 and $401.8 \mathrm{~J} / \mathrm{m} 2$. Our results show an occupational solar UVR exposure of uncovered skin exceeding the suggested occupational limit of 1-1.3 standard erythemal dose per day, in all longshoremen. In one case this value was exceeded also in one of the port traffic coordinators /good acceptors, despite the overall lower UVR doses received. In conclusion, our UV measurement campaign in a group of Italian dock-workers support the existence of a significantly high occupational UVR risk at least for longshoremen, possibly inducing long-term UV-related adverse skin effects. Accordingly, an effort for the development of adequate interventions to protect these workers from solar UV risk is highly recommended in Italy.
\end{abstract}

Keywords-ultraviolet radiation, occupational exposure, dosimetry, dock-workers, solar radiation

\section{INTRODUCTION}

Solar ultraviolet radiation (UVR) exposure is a recognized occupational risk factor, even if usually not adequately considered, for all the activities performed outdoor, as the ones in the maritime and in the port sectors. UVR may induce relevant adverse health effects, and in particular long-term effects, including:

- skin cancers: UVR is among the most important risk factors for cutaneous melanoma, in case of intense intermittent exposure and repeated sunburns, and for keratinocyte carcinomas (KC), including basal cell carcinoma (BCC) and squamous cell carcinoma (SCC), associated to chronic exposure [1, 2, 3];

- other skin diseases as actinic keratosis (AK), that can be also considered in situ SCC, and photo-aging [4, 5, 6];

- ocular diseases as cataract, pterygium, and possibly macular degeneration $[7,8,9]$;

- possibly other types of adverse effects, including effects on immune systems and other apparatus $[4,10]$.

In particular for $\mathrm{KC}, \mathrm{AK}$, photoaging, cataract and pterygium several scientific studies have shown relevant associations of these outcomes with outdoor work [2, 3, 4, 7, 8 ], even if more research is needed on the association of occupational solar UVR exposure with other adverse effects, as macular degeneration [9], and on the evaluation of the harmful UVR exposure levels to be considered $[4,11,12$, 13]. Among the main limitations of the scientific studies in this field there are the difficulties in adequately estimating the cumulative UV dose of the workers with reliable methods $[12,13,14]$.

Considering short-term UVR exposure of outdoor workers, there are many examples in scientific literature, revealing high or very high exposure levels, even if most of them in sectors as agriculture and construction [4], while few studies investigated the maritime workers $[6,13,15,16,17]$. and very few the docks sector [16]. The latter activity, in particular, is of relevance from the point of view of solar UV 
exposure as usually it is mainly performed on water, or closed to water, i.e. to a UVR reflecting surface able to increase UV irradiance, according to the albedo phenomenon $[4,11,13]$. Accordingly this sectors is of interest, and should be particularly considered for the UV risk evaluation, and the development of effective preventive interventions.

For these reasons, aim of our study was to collect individual solar UVR exposure measurements with personal dosimeters in a group of dock-workers from North-East Italy, investigating different exposure levels according to the job tasks, and comparing personal measurements with ambient exposure.

\section{MATERIALS AND METHODS}

We collected individual solar UVR exposure data with personal electronic dosimeters in a group of volunteer dockworkers (DW) of the port of Trieste, a city in the North-East of Italy $\left(45^{\circ} 38^{\prime} \mathrm{N}, 13^{\circ} 48^{\prime} \mathrm{E}\right)$. The exposure during a full working day, the 4th of July 2018, was sampled. The effective (erythemal) radiant exposure at the horizontal plan provided by the European Space Agency (http://www.temis.nl/uvradiation/archives/v2.0/2018/07/uvde f20180704_wd.gif) based on the local weather conditions in that day was approximately $4.5 \mathrm{~kJ} / \mathrm{m}^{2}$. The personal UVR exposure was measured using 10 Gigahertz-Optik X2000 and X2012 series electronic dosimeters, and a GigahertzOptik BTS2048-UV-S spectroradiometer. The method for calibration and standardization of the measures is the same previously reported in another UV exposure measurement campaign [17], considering the different weighting of the dosimeters. The dosimeters have been placed on the upper part of the back, or on the chest of the DWs, avoiding any interference with the usual work activity. The spectroradiometer was placed at the workplace on the quay (Fig. 1). Furthermore, one of the member of the research group worn an ocular UV dosimeter fixed on a stem of the sunglasses; this subject spent the whole morning of the sampled day following the DWs engaged as longshoremen during their usual working tasks (Fig. 1).

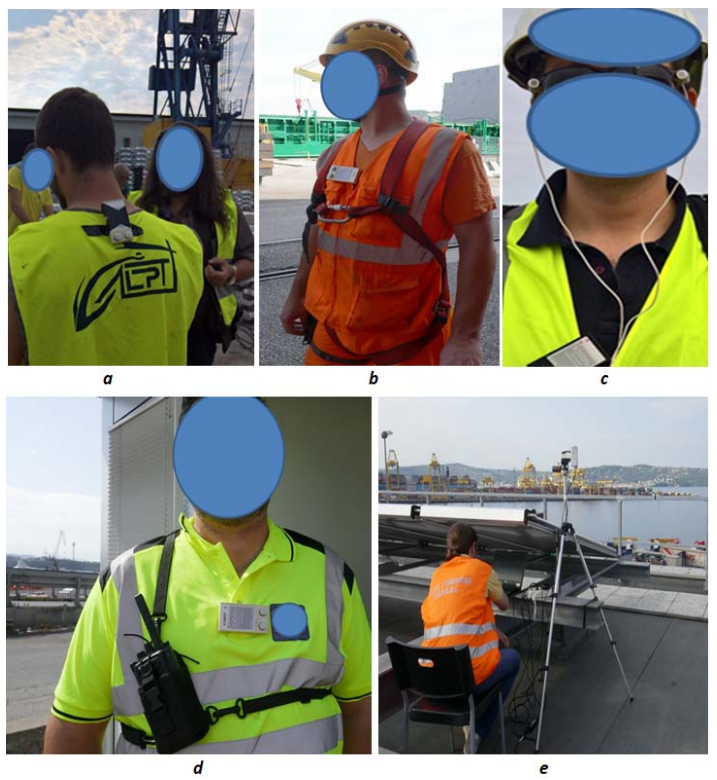

Fig. 1. UV electronic dosimeters used for the evaluation of personal solar UVR exposure in the group of dock-workers: a) longshoreman with back dosimeter; b) longshoreman with chest dosimeter; c) researcher with ocular dosimeter; d) port traffic coordinator / goods acceptor with chest dosimeter; e) spectroradiometer for environmental UV dose measurements.
For the researcher we calculated also the non-weighted solar UV-A ocular dose, and accordingly we were able to estimate the approximately ocular UV-A dose at the eyes of the longshoremen (who whore in the nearby of the researcher), considering the proportions between the exposure period of the researcher and of the workers, but we were not allowed to estimate the ocular dose of the traffic coordinators / goods acceptors, as their activities were different, with lower UVR exposure and performed in another area of the port.

We evaluated the solar UVR exposure of 14 DWs, 10 longshoremen (DW1-DW10) and 4 working as port traffic coordinators/goods acceptors (DW11-DW14), as following:

- DW1 and DW2: longshoremen with a full day working shift (8 a.m.-5 p.m.), dosimeters placed on the back;

- DW3, DW4, DW5, DW6: longshoremen with a half-day morning shift (8 a.m.-1 p.m.), dosimeters on the back;

- DW7: longshoreman with a half-day morning-early afternoon shift (10 a.m.-3 p.m.), dosimeter on the chest;

- DW8, DW9 and DW10: longshoremen with a half-day afternoon shift (1 p.m.-5 p.m.), dosimeters on the back;

- DW11 and DW12: port traffic coordinators / goods acceptors with a half-day morning shift (8 a.m.-1 p.m.), dosimeters placed on the chest;

- DW13 and DW14: port traffic coordinators / goods acceptors with a half-day afternoon shift (1 p.m.-5 p.m.), dosimeters placed on the chest.

The measurements were organized within a preventive campaign for the evaluation of the occupational risk in various occupational activities according to the Italian national occupational health and safety legislation, and were also aimed to the development of more adequate information and training of the workers. All the ethic principles considered in the Helsinki declaration were followed.

\section{RESULTS}

The results of the individual solar UV exposure measurements collected in DWs are reported in Table 1. Each exposure value measured is referred to the specific body district (chest or back) and to the specific working time of the workers, and is compared to the environmental UV dose measured on the horizontal plane with the spectroradiometer (Tab. 1). The ocular dose registered on the sunglasses of the researcher spending the whole morning close to the longshoremen was, not surprisingly, the lowest measured in terms of erythemal dose, resulting of $0.86 \mathrm{~J} / \mathrm{m} 2$, detected with a length of the measured period of 226 minutes, representing only the $0.04 \%$ of the respective environmental effective radiant exposure of $1922 \mathrm{~J} / \mathrm{m} 2$. The non-weighted UV-A dose at the eyes resulted of $209.5 \mathrm{~J} / \mathrm{m} 2$. According to this, we estimated the non-weighted UV-A doses received at the eyes of the longshoremen, resulted between 133.9 and $401.8 \mathrm{~J} / \mathrm{m} 2$ (Tab. 1). Considering erythemal skin exposure, the results show a significantly higher exposure in longshoremen compared to port traffic coordinators/ good acceptors. The maximum exposure was measured, not surprisingly, on the back of one of the two workers employed as longshoremen for a full day, resulting $1975 \mathrm{~J} / \mathrm{m} 2$ (about 20 Standard Erythemal Doses - SED) in approximately 7 hours and 30 minutes (Tab. 1). 
TABLE I. OCCUPATIONAL SOLAR UVR EXPOSURE OF A GROUP OF DOCK-WORKERS (DW) IN TRIESTE, NORTH-EAST ITALY, ON THE 4TH JULY 2018, MEASURED WITH PERSONAL DOSIMETERS PLACED ON THE BACK OR ON THE CHEST COMPARED WITH THE ENVIRONMENTAL UV EFFECTIVE RADIANT EXPOSURE IN THE SAME PERIOD, AND ESTIMATED NON-WEIGHTED UV-A OCULAR DOSE

\begin{tabular}{|c|c|c|c|c|c|c|c|}
\hline Work & & $\begin{array}{l}\text { Placement } \\
\text { of the } \\
\text { dosimeter }\end{array}$ & \begin{tabular}{|c|} 
Working period \\
$/$ length of the \\
period measured \\
(minutes)
\end{tabular} & \begin{tabular}{|c|} 
Personal UV \\
erythemal \\
dose $(\mathrm{J} / \mathrm{m} 2$ / \\
SED) \\
\end{tabular} & $\begin{array}{c}\text { Estimated non- } \\
\text { weighted UV-A } \\
\text { ocular dose } \\
(\mathrm{J} / \mathrm{m} 2) \\
\end{array}$ & $\begin{array}{c}\text { Corresponding } \\
\text { environmental UV } \\
\text { effective radiant } \\
\text { exposure }\left(\mathrm{H}_{\text {eff }}\right)(\mathrm{J} / \mathrm{m} 2)\end{array}$ & $\begin{array}{l}\text { Personal } \\
\text { erythemal vs. } \\
\text { ambient UVR } \\
\text { exposure (\%) }\end{array}$ \\
\hline & DW1 & Back & Full-day / 432 & 1975 / 19.8 & 401.8 & 3339 & 59 \\
\hline & DW 2 & Back & Full-day / 417 & $1067 / 10.7$ & 387,8 & 3276 & 32 \\
\hline & DW 3 & Back & Morning / 144 & $288 / 2.9$ & 133.9 & 857 & 33 \\
\hline$Z_{0}$ & DW 4 & Back & Morning / 191 & $402 / 4.0$ & 177.6 & 1322 & 30 \\
\hline 点 & DW 5 & Back & Morning / 243 & $257 / 2.6$ & 226.0 & 1596 & 16 \\
\hline$\sqrt{0}$ & DW 6 & Back & Morning / 251 & 854 / 8.5 & 233.4 & 1965 & 43 \\
\hline 0 & DW 7 & Chest & $\begin{array}{l}\text { Morning \& early } \\
\text { afternoon / } 260\end{array}$ & $551 / 5.5$ & 241.8 & 2675 & 20 \\
\hline & DW 8 & Back & Afternoon / 246 & $622 / 6.2$ & 228.8 & 2191 & 28 \\
\hline & DW 9 & Back & Afternoon / 226 & $458 / 4.6$ & 210.2 & 2001 & 22 \\
\hline & $\begin{array}{c}\text { DW } \\
10\end{array}$ & Back & Afternoon / 225 & $413 / 4.1$ & 209.2 & 1981 & 20 \\
\hline$\overline{\mathscr{N}}$ & $\begin{array}{l}\text { DW } \\
11\end{array}$ & Chest & Morning / 177 & $48 / 0.5$ & / * & 1550 & 3 \\
\hline 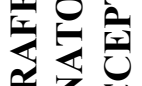 & $\begin{array}{l}\text { DW } \\
12\end{array}$ & Chest & Morning / 193 & $139 / 1.4$ & /* & 1759 & 7 \\
\hline 숭 & $\begin{array}{c}\text { DW } \\
13\end{array}$ & Chest & Afternoon / 210 & $89 / 0.9$ & /* & 1876 & 4 \\
\hline 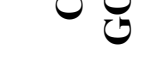 & $\begin{array}{l}\text { DW } \\
14\end{array}$ & Chest & Afternoon / 248 & $44 / 0.4$ & /* & 2045 & 2 \\
\hline
\end{tabular}

*It was not possible to estimate the non-weighted UV-A ocular dose of port traffic coordinators / goods acceptors, as the reseacrher wearing a dosimeter on thesunglasses' stem was standing nearby the longshoremen

A high exposure of $551 \mathrm{~J} / \mathrm{m} 2$ in 260 minutes was measured also on the chest of the longshoreman working in the late morning/early afternoon, i.e. during the central hours of the day with a more intense solar UVR. Variable exposures at the back, apparently not strongly related to the length of the period measured, have been observed for DW3, DW4, DW5 and DW6, working as longshoremen in the morning, with measured personal exposures ranging between 257 and $854 \mathrm{~J} / \mathrm{m} 2$. Quite high exposures at the back varying between 413 and $622 \mathrm{~J} / \mathrm{m} 2$ have been observed for longshoremen DW8, DW9 and DW10, who worked in the afternoon. As anticipated, the exposure during both, the morning and the afternoon shift, was much lower in port traffic coordinators / goods acceptors: between 44 and 139 $\mathrm{J} / \mathrm{m} 2$ at the chest respectively for DW14 and DW12.

Considering ambient exposure, the maximum theoretical daily exposure registered with the spectroradiometer according to the working period of the worker with the longest shift (DW1) was $3339 \mathrm{~J} / \mathrm{m} 2$. DW1 is also the worker receiving the highest percentage of the theoretical daily ambient exposure: the $59 \%$. The percentages of individual vs. ambient exposure of the other longshoremen varied between the 16 and the $43 \%$, both registered at the back and during the morning, respectively for DW5 and DW6. Lower percentages of personal vs. environmental exposure have been calculated at the chest for the port traffic coordinators / 
goods acceptor, varying between the 2 and $7 \%$, and at the eyes of the researcher, where the percentage of individual vs. ambient exposure was only the $0.04 \%$ (Tab. 1).

\section{DISCUSSION}

Our results on personal solar UVR exposure, measured in a group of dock-workers (DWs) of North-East Italy during a Summer working day show remarkable high UV exposure levels in longshoremen: the UV doses collected in this group varied between $2.6 \mathrm{SED} /$ half-day and $20 \mathrm{SED} /$ day, where 1 SED is equal to $100 \mathrm{~J} / \mathrm{m} 2$ [11]. Notably, these results were obtained with the $80 \%$ of the measurements lasting only half of the working day. Regarding the body districts evaluated, in the $90 \%$ of the cases we were able to place the dosimeter on the back of the longshoremen. For the longshoreman investigated with a dosimeter on the chest we registered a quite high exposure of $5.5 \mathrm{SED} /$ half-day, comparable with the doses measured on the back of workers active in the same period. Considering the other activity performed by the DWs, we evaluated the exposure of four port traffic coordinators/goods acceptors. In this case we placed the dosimeters only on workers' chests, as they frequently had to seat at a desk inside a cabin, in order to register the accesses to the port area, and validate the forms for the truck drivers carrying goods to be loaded on or unloaded from the ships; accordingly, the activity of this type of DWs was performed even partially indoor, and it could be classified as a mixed outdoor/indoor job. Nevertheless, for these DWs we registered exposure between 0.4 and $1.4 \mathrm{SED} /$ half-day.

Comparing our data with a previous investigation performed in a group of Danish dockworkers [16], we found higher exposures in Italy, at a lower latitude. Grandahl et al. found in July a median daily UV exposure of 0.9 SED, more similar to the one we detected for the port traffic coordinators/goods acceptors. Unfortunately, there is not a detailed description in this Danish study of the specific working activity performed by the dockworkers, but, in addition to the type of the activity and to the role of the latitude and of the different environmental erythemal UV doses between Denmark and Italy, also other factors may have played a role. Among other, Grandahl et al. used different types of dosimeters that, furthermore, were applied to the dorsal side of the wrist or lower arm: the different placement of the meters in this Danish study [16] compared to the dosimeters placed on the back or on the chest in the present study is a possible explanation of the difference.

Considering now the comparison between the personal UV exposure we collected in DWs with a proposed limit value for occupational solar UVR exposure of 1-1.3 $\mathrm{SED} /$ day (i.e. a value obtained from a transposition in the erythema action spectrum of the Threshold Limit Value of the American Conference of Governmental Industrial Hygienists [18-20]), we detected a relevant exceeding of this value (Fig. 2). It should be noted that in Europe, the current available International Commission on Non-Ionizing Radiation protection (ICNIRP) limits for artificial UVR exposure are of $30 \mathrm{~J} / \mathrm{m} 2$ for the whole UV spectrum (even if the ICNIRP exposure limit value is an expression of effective radiant exposure, as well as the SED, the two physical quantities have different spectral weightings, but, with good approximation, 1 SED can be considered equal to three times the ICNIRP limit), and of $10^{4} \mathrm{~J} / \mathrm{m} 2$ for the non-weighted UV-A ocular dose received during a 8-hours work-day [11].

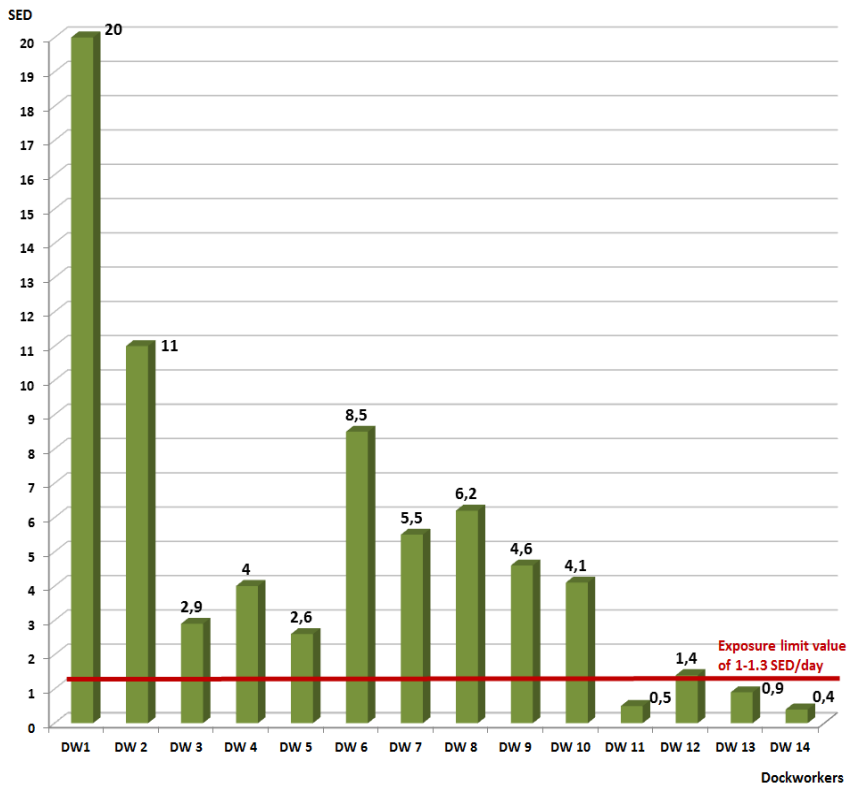

Fig. 2. Occupational exposure to solar UV radiation of the Italian dockworkers during the work-shift reported in Standard Erythemal Doses (SED) compared to the proposed limit value of 1-1.3 SED/day.

As anticipated, we observed a systematic exceeding of the values of 1-1.3 SED for all the longshoremen, even if 8 of them have been measured only for less than four hours, and in one case we detected an overcoming of the limit even for a port traffic coordinator/goods acceptor (DW12), even if engaged only partially in outdoor activities and, again, sampled for half of the working-day only (Fig. 2).

Considering the ocular exposure, we estimated a nonweighted UV-A ocular dose at the longshoremen' eyes between 133.9 and $401.8 \mathrm{~J} / \mathrm{m} 2$, i.e. between the 1.3 and the $4 \%$ of the ICNIRP non-weighted UV-A limit. This means that a DW during a working day may have an ocular exposure up to the $4 \%$ of the limit: these levels of ocular exposure were lower than those we observed with the same methodology in a group of fishermen, where the individual eye exposure measured resulted as up to the $30 \%$ of the limit [17]. This difference can be explained with the less important role of water reflections for dockworkers compared to fishermen and also with the different sun angles during the two types of working activities (fishing is often performed with sun angles on the horizon below $45^{\circ}$, increasing a possible direct ocular UVR exposure) [17]. Furthermore, these quite low ocular exposure levels indicate the natural habit for outdoor workers of performing their activities avoiding direct sunlight in the face, reducing excessive exposure and glares. Even if the eye exposure we estimated for dockworkers was quite low, there is still a strong indication for the adoption of adequate eye protections, considering that UVR may act on the eye both with acute effects, as photo-keratitis, possibly responsible also of workrelated eye injuries $[4,23]$, but also with chronic effects $[4$, $7,8]$, which may possibly appear also for prolonged exposures below the limits.

Discussing now the relations between individual and environmental solar UVR skin exposure, we found some variability within personal UV doses for longshoremen, possibly related to the different working postures adopted and to other factors, as the distance from reflecting surfaces (e.g. water) and the presence of shades (e.g. the shaded 
determined by the ship docked). When excluding the maximum and the minimum value, we found that the $80 \%$ of the longshoremen received a percentage of the environmental cloud-modified erythemal UV dose measured with our spectroradiometer between the 20 and the $43 \%$, and of the $28.8 \%$ on average (Tab. 1). In order to better understand this quite high variability it would be important to collect detailed information on environmental and individual factors influencing the exposure with an integrated method, as previously observed $[4,13]$. Various algorithms have been proposed, aimed at reconstructing the solar UVR dose received by outdoor workers in different conditions, considering in particular also the exposure of different body districts [12-14, 21], and one of this has been recently validated [21]. It would be important also to validate a specific questionnaire for the collection of solar UVR exposure data, similar to the one we previously applied [5, 13], but adequately translated in the national languages and validated with an appropriate comparison, as it happened for other occupational risks [22]. This kind of questionnaires, integrated with the validated algorithms proposed, would allow a better understanding of the variability of individual solar UVR exposure, a more adequate prediction of the exposure levels and, consequently, the possibility to reconstruct long-term exposure history, studying also the relation with possible health effects.

We definitely found a lower variability between personal and ambient UV exposure for port traffic coordinators/goods acceptors compared to longshoremen. In fact, we observed percentages of individual vs. environmental exposure between the 2 and the $7 \%$ (Tab. 1). This more stable exposure pattern is coherent with a minor variability of the activities performed by these dockworkers, compared to the longshoremen, and also with the less variable work environment around the workers, mainly performed in a more specific location of the dock, frequently in positions shadowed by a prefabricated cabin, and mainly surrounded by asphalt.

Summarizing, our data are, to the best of our knowledge, the first Italian data demonstrating an intense solar UVR dose received by dockworkers' skin in Summer: these data, supported by other results indicating an excessive risk of skin pre-cancerous and cancerous lesions in outdoor workers [2, 3 ], indicate an urgent need to improve sun protection campaigns and skin cancer prevention in occupational settings in Italy, including dockworkers, and in particular longshoremen. Interestingly, in the same area where we performed our solar UVR exposure measurements, a recent case-control study reported a significantly increased Odd Ratio of 4.3 (C.I. 95\% 1.1-16.4) for maritime workers to develop keratinocyte carcinomas compared to unexposed workers [24]. It should be noted that UV-induced occupational skin cancers in Italy, as well as in other European countries, are highly under-reported, with few cases per year notified to the workers compensation Authority compared to the number of expected cases [25].

\section{CONCLUSIONS}

We measured high individual solar UVR exposure levels at the beginning of the Summer in a group of dockworkers employed as longshoremen in a company working at the port of a North-East Italian city. Lower but still relevant exposures have been found for dockworkers engaged as port traffic coordinators/goods acceptors. The UV exposure levels detected may be harmful, in particular for the skin in case of long-term repeated exposures. As a final remark, the UV exposure levels we detected in our study may indicate the need of more adequate prevention initiatives to manage occupational solar UVR risk for Italian dockworkers

\section{ACKNOWLEDGMENT}

We are very grateful to the Port Authority of the city of Trieste and to the dock-workers company, as well as to the University and the Dept. of Prevention-A.S.U.I.T.S of Trieste for permitting us to perform this investigation. We thank also all the resident physicians in Occupational Medicine of the University of Modena and of Trieste who collaborated to the measurements campaign, together with the researchers of "Sapienza" University and of the Italian Workers' Compensation Authority (INAIL).

\section{REFERENCES}

[1] B. K. Armstrong, and A. E. Cust, "Sun exposure and skin cancer, and the puzzle of cutaneous melanoma: A perspective on Fears et al. Mathematical models of age and ultraviolet effects on the incidence of skin cancer among whites in the United States. American Journal of Epidemiology 1977; 105: 420-427”, Cancer. Epidemiol. Vol. 48, pp. 147-156, 2017.

[2] A. Bauer, T.L. Diepgen, and J. Schmitt, "Is occupational solar ultraviolet irradiation a relevant risk factor for basal cell carcinoma? A systematic review and meta-analysis of the epidemiological literature", Br. J. Dermatol., vol. 165, pp. 612-625, 2011.

[3] J. Schmitt, A. Seidler, T.L. Diepgen, and A. Bauer, "Occupational ultraviolet light exposure increases the risk for the development of cutaneous squamous cell carcinoma: A systematic review and metaanalysis", Br. J. Dermatol., vol. 164, pp. 291-307, 2011.

[4] A. Modenese, L. Korpinen, and F. Gobba, "Solar Radiation Exposure and Outdoor Work: An Underestimated Occupational Risk," Int. J. Environ. Res. Public. Health., vol. 15(10), pp. pii: E2063, September 2018.

[5] A. Modenese, F. Farnetani, A. Andreoli, G. Pellacani, and F. Gobba, "Questionnaire-based evaluation of occupational and nonoccupational solar radiation exposure in a sample of Italian patients treated for actinic keratosis and other non-melanoma skin cancers," J. Eur. Acad. Dermatol. Venereol., vol. 30(supp.3), pp. 21-26, April 2016.

[6] M. Oldenburg, B. Kuechmeister, U. Ohnemus, X. Baur, and I. Moll, "Actinic keratosis among seafarers", Arch. Dermatol. Res., vol. 305, pp. 787-796, 2013.

[7] A. Modenese, and F. Gobba, "Cataract frequency and subtypes involved in workers assessed for their solar radiation exposure: a systematic review," Acta. Ophthalmol., vol. 96(8), pp. 779-788, December 2018.

[8] A. Modenese, and F. Gobba, "Occupational Exposure to Solar Radiation at Different Latitudes and Pterygium: A Systematic Review of the Last 10 Years of Scientific Literature," Int. J. Environ. Res. Public. Health., vol. 15(1), pp. pii: E375, December 2017.

[9] A. Modenese, and F. Gobba, "Macular degeneration and occupational risk factors: a systematic review," Int. Arch. Occup. Environ. Health., vol. 92(1), pp. 1-11, January 2019.

[10] Hart, P.H.; Norval, M. Ultraviolet radiation-induced immunosuppression and its relevance for skin carcinogenesis. Photochem. Photobiol. Sci. 2018, 17, 1872-1884.

[11] International Commission on Non-Ionizing Radiation Protection (ICNIRP), "Icnirp statement - protection of workers against ultraviolet radiation," Health. Phys., vol. 99, pp. 66-87, July 2010.

[12] M. Borra, C. Grandi, A. Militello, C. Burattini, L. Gugliermetti, et al. "Developing an Algorithm to Assess the UV Erythemal Dose for OutdoorWorkers", Proceedings of the 2018 IEEE International Conference on Environment and Electrical Engineering and 2018 IEEE Industrial and Commercial Power Systems Europe (EEEIC/I\&CPS Europe), Palermo (Italy), 12-15 June 2018. 
[13] A. Modenese, F. Bisegna, M. Borra, C. Grandi, F. Gugliermetti, et al., "Outdoor work and solar radiation exposure: Evaluation method for epidemiological studies," Med. Pr., vol. 67(5), pp. 577-587, April 2016.

[14] M. Wittlich, S. Westerhausen, P. Kleinespel, G. Rifer, and W Stöppelmann, "An approximation of occupational lifetime UVR exposure: algorithm for retrospective assessment and current measurements," J. Eur. Acad. Dermatol. Venereol. vol. 30 (supp. 3), pp. 27-33, April 2016.

[15] U. Feister, G. Meyer, and U. Kirst, "Solar UV exposure of seafarers along subtropical and tropical shipping routes", Photochem. Photobiol, vol. 89, pp. 1497-1506, 2013.

[16] K. Grandahl, P. Eriksen, K.S. Ibler, J.P. Bonde, and O.S. Mortensen, "Measurements of Solar Ultraviolet Radiation Exposure at Work and at Leisure in Danish Workers", Photochem. Photobiol., vol. 94(4), pp. 807-814, July 2018.

[17] A. Modenese, F.P. Ruggieri, F. Bisegna, M. Borra, C. Burattini, et al., "Occupational Exposure to Solar UV Radiation of a Group of Fishermen Working in the Italian North Adriatic Sea,” Int. J. Environ. Res. Public. Health., vol. 16(16), pp. pii: E3001, August 2019.

[18] Sun Safety at Work Canada working group., "Solar UV Radiation Risk Assessment for Outdoor Workers: Technical Guide", Sun Safety at Work Canada, School of Occupational and Public Health Ryerson University 350 Victoria Street Toronto, Ontario, M5B2K3 Canada. Available online at: www.occupationalcancer.ca/wpcontent/uploads/2016/03/SSAWC-UV-Risk-Assessment-TechnicalGuide.pdf (last access 19th March 2020)

[19] M. Silva Paulo, B. Adam, C. Akagwu, I. Akparibo, R.H. Al-Rifai, S. Bazrafshan, et al., "WHO/ILO work-related burden of disease and injury: Protocol for systematic reviews of occupational exposure to solar ultraviolet radiation and of the effect of occupational exposure to solar ultraviolet radiation on melanoma and non-melanoma skin cancer," Environ. Int., vol. 126, pp. 804-815, May 2019.

[20] T. Tenkate, B. Adam, R.H. Al-Rifai, B.R. Chou, F. Gobba, et al., "WHO/ILO work-related burden of disease and injury: Protocol for systematic reviews of occupational exposure to solar ultraviolet radiation and of the effect of occupational exposure to solar ultraviolet radiation on cataract," Environ. Int., vol. 125, pp. 542-553, April 2019.

[21] G. Salvadori, D. Lista, C. Burattini, L. Gugliermetti, F. Leccese, and F. Bisegna, "Sun Exposure of Body Districts: Development and Validation of an Algorithm to Predict the Erythemal Ultra Violet Dose", Int. J. Environ. Res. Public. Health., vol. 16(19), pp.pii: E3632, September 2019.

[22] F. Gobba, R. Ghersi, S. Martinelli, A. Richeldi, P. Clerici, P. Grazioli, "Italian translation and validation of the Nordic IRSST standardized questionnaire for the analysis of musculoskeletal symptoms", Med. Lav., vol. 99(6), pp. 424-43, December 2008.

[23] F. Gobba, E. Dall'Olio, A. Modenese, M. De Maria, L. Campi, and G. M. Cavallini, "Work-Related Eye Injuries: A Relevant Health Problem. Main Epidemiological Data from a Highly-Industrialized Area of Northern Italy", Int. J. Environ. Res. Public. Health., vol. 14(6), pp. E604, June 2017.

[24] F. Larese Filon, M. Buric, and C. Fluehler, "UV exposure, preventive habits, risk perception, and occupation in NMSC patients: A casecontrol study in Trieste (NE Italy)", Photodermatol. Photoimmunol. Photomed., vol. 35(1), pp. 24-30, January 2019.

[25] F. Gobba, A. Modenese, and S.M. John, "Skin cancer in outdoor workers exposed to solar radiation: a largely underreported occupational disease in Italy," J. Eur. Acad. Dermatol. Venereol., vol. 33(11), pp. 2068-2074, December 2019. 